\title{
Innovative fabrication of diffractive surfaces on plastic parts via textures micromilled on NiP injection moulds
}

\author{
Nicola Milan ${ }^{1} \cdot$ Paolo Parenti $^{2} \cdot$ Massimiliano Annoni $^{2} \cdot$ Marco Sorgato $^{1} \cdot$ Giovanni Lucchetta $^{1}$
}

Received: 14 September 2020 / Accepted: 24 January 2021 / Published online: 4 February 2021

(C) The Author(s) 2021

\begin{abstract}
Diffractive microstructured surfaces are nowadays increasingly applied to polymeric parts for aesthetic, security and optical functionalities. However, both the machining of the mould blaze-grating and its replication on plastic are still representing challenging issues, from both the technical and economical points of view. In this work, an innovative process chain based on carbide tools micromilling of mould gratings was developed for mass production of diffractive patterns on injection moulded parts. A micromilling experimental campaign was conducted on a nickel-phosphorus (NiP) thick coating to machine a blazegrating on the mould surface, evaluating the influence of the cutting parameters on the diffractive surface quality. Subsequently, the microstructures were replicated on ABS, PC and PMMA by injection moulding. The roughness parameters Sk, Spk and Svk were added with the idea that their sum is representative of the polymer replication of regular diffraction grating pattern. Moreover, the effect of the moulded grating surface quality on the optical performance was preliminarily assessed. The obtained results show that the proposed process chain is suitable for low-cost mass production of polymeric parts with diffractive microstructures.
\end{abstract}

Keywords Blaze-grating $\cdot$ Micromanufacturing $\cdot$ Process chain $\cdot$ Texturing $\cdot$ Surface characterization $\cdot$ Micromilling · Microinjection moulding

\section{Introduction}

Nowadays, challenging issues are represented by the functionalization of the polymer surface to guarantee the mass production of components with optical functionalities. Microstructured polymer products are widespread in several industrial fields such as optics, medicine, security and sensing applications [1,2]. Diffractive microfeatures ensure the optical performance that is needed in several applications thanks to their unique capacity of controlled light diffraction.

Typically, microstructured moulds are used for mass production of optically functionalized polymers. In years, both mechanical and thermal manufacturing methods have been used for making diffractive surfaces on moulds. Diffraction

Paolo Parenti

paolo.parenti@polimi.it

Dept. of Industrial Engineering, Università di Padova, Padova, Italy

2 Dept. of Mechanical Engineering, Politecnico di Milano, Milano, Italy gratings are fundamental devices in spectroscopy due to their capability to disperse polychromatic light into its constituent monochromatic components [3].

During the past decades, many non-mechanical approaches have been considered for the fabrication of high-resolution diffraction gratings, including focused ion beam [4], interferential lithography [5], electron-beam lithography (also in combination with reactive ion etching) [6] and laser writing [7]. However, these technologies could be mainly applied to planar substrates or large curvature radius concave/convex surfaces [8]. Moreover, they required specialized operators, dedicated machines/instrumentations and many-steps protocols that are in contrast with the industrial needs of production cost reduction.

In recent years, multi-axis diamond machining was implemented as an alternative approach to electron-beam lithography [9] and in general, the diamond machining processes for generating functional surface structures have obtained in these years large attention [10-12].

Holthusen et al. [13] exploited the diamond turning technology using a monocrystalline diamond tool applied on a nano Fast Tool Servo to obtain blaze diffractive optics (Pitch 
$10 \mu \mathrm{m}$, Height $1 \mu \mathrm{m}$ ) with an excellent surface finish on a planar mould insert. Sun et al. [8] introduced a method called ultra-precision side milling to realize diffractive structures for infrared hybrid micro-optics with one step generation process. This technology allowed the achievement of complex hierarchical structures on freeform surfaces with high accuracy using a single diamond tool fixed on a high-speed spindle with an adaptable swing radius. $\mathrm{Lu}$ et al. [1] proposed a precise micro grinding machining to manufacture an array of micro grooves on the surface of a mould core for microinjection moulding. The V-groove depth varied from 99.72 to 153.93 $\mu \mathrm{m}$, with a spacing of about 400 to $600 \mu \mathrm{m}$.

Obtaining diffractive surfaces with micromilling is possible but presents challenging aspects due to the nature of the removal process. Obtaining sharp-edged micro-cavities in optical quality can be achieved by micromilling by only managing different aspects. First, the accessibility of the surface must be guaranteed giving to the tool approach and retraction enough space to occur without limits. On the other, diffractive surfaces require accuracy and tolerances in the micrometric range. Therefore, they require ultra-accurate machines with extreme positioning repeatability, capable of machining quite large surfaces in free form. When large surfaces need to be machined, long machining times are required and therefore, the tool wear, and its consequences on the process output, is an important issue [14]. Tiny tools (with large axial accessibility and small diameters) must be adopted, exacerbating the impact of tool bending on the machined surface response [15]. Diamond milling with monocrystalline diamond tools is surely producing the best performances but at high costs and additional limitations related to the more accurate machine setting needed [10]. Diamond tools are in fact more vulnerable to misalignments in the mounting and positioning and to temperature and structural stability (e.g. process-induced vibrations) $[11,12]$. With these tools, the spindle configuration plays a key role and predictability of tool wear can be inherently limited. Carbide tools are more robust from these points of view, but typically show less process performance hence requiring more optimized cutting parameters [14].
Small chip thicknesses must be adopted to minimize tool deflections, but burr formation and minimum chip thickness effects (such as striations and ploughing surface marks) are prone to be generated because of that [14]. Material behaviour is another issue that has a big impact on mould micromilling and the consequent microinjection moulding responses [16]. Very hard materials typically lead to a better surface appearance but induce higher forces and higher tool wear, thus limiting the process stability and accuracy. Softer materials are easier to machine, but their increased elastic recovery and ploughing tendency limit the process output. For these reasons, micromilling of coated moulds with thick nickelphosphorous (NiP) coatings recently demonstrated to generate extremely low roughness in the nanometric range [17].

However, only a few attempts are found in literature about diffractive micromilling applications. Li et al. [18] presented a micromilling strategy to obtain a mould surface with optical microstructures, achieving a blaze-grating with a Pitch of $50 \mu \mathrm{m}$ and a Height of about $3.3 \mu \mathrm{m}$. As regards the surface roughness, $\mathrm{Sa}=49.96 \mathrm{~nm}$ was obtained.

In order to make the optical functionalization suitable for mass production, a replication of the microfeatures using injection moulding technology is necessary [10]. Furthermore, Kalima et al. [19] showed how the choice of the correct type of material is essential to reach a high replication fidelity. Moulded PC, COP, HFP-TFE-Et and SAN microfeatures were characterized. The PC gave the best performance in terms of replicability while the SAN the poorest. Holthusen et al. [13] compared the replication of PMMA, COP and COC blaze-gratings, obtaining the best result with the PMMA, although this material was showing the higher viscosity at melting temperature.

However, the full testing of a complete process chain to fabricate diffraction gratings for polymer components through micromilling has not been attempted yet. In this work, ABS, PC and PMMA blaze-grating were injection moulded by adopting a specifically micromilled diffractive mould. The influence of the machining parameters on both the diffractive microstructure quality and the replication of the mould was evaluated by measuring the structures with an optical

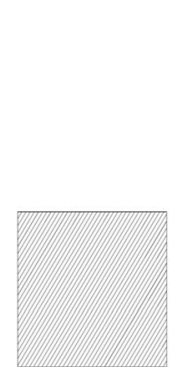

a)

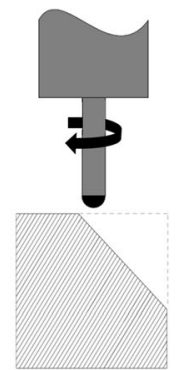

b)

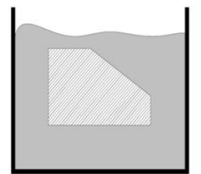

c)

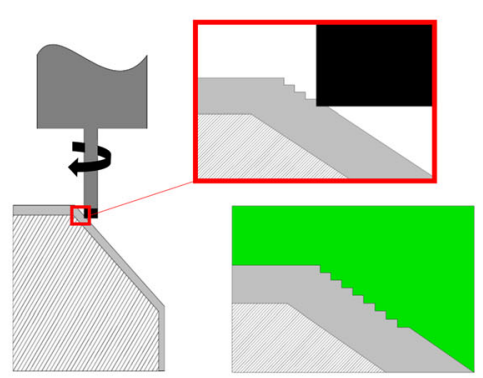

d)

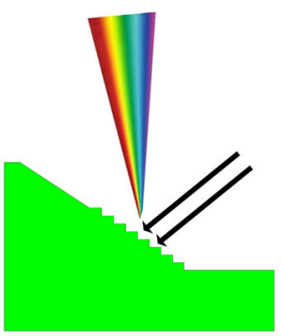

f)

Fig. 1 Process chain for obtaining diffraction gratings on injected polymer components: (a) steel mould, (b) steel milling, (c) NiP coating, (d) NiP milling, (e) injection moulding, (f) light diffraction on plastic part 

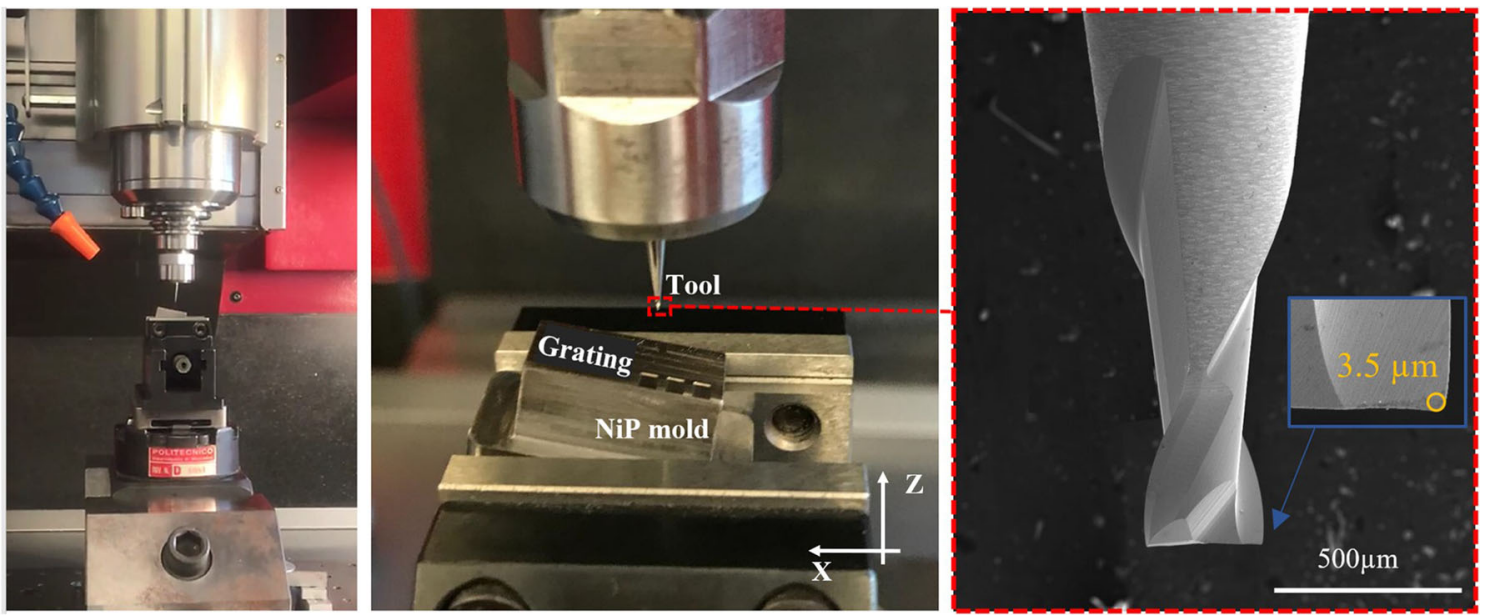

Fig. 2 Mould micromilling setup

profilometer. Moreover, the optical performance of the diffraction gratings was preliminarily assessed, evaluating the proposed process chain.

\section{Diffraction gratings}

Micro-optical gratings can be used to generate light diffraction. Gratings are period arrangements of two-dimensional microstructures with a defined shape. The diffraction response is led by the geometry of the grooves (e.g. rectangular, triangular, etc.) and their orientation in the components. Blazegratings possess prismatic concave profiles with an infinite extension, usually indicated as a saw-tooth-like structure.

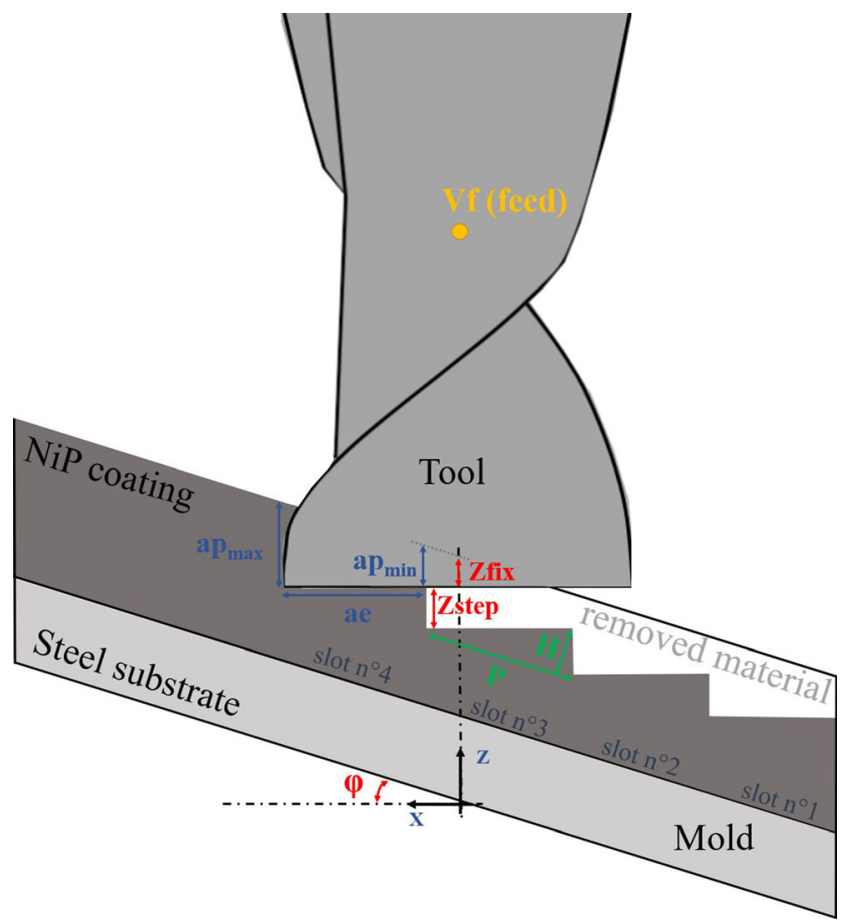

Fig. 3 Cutting configuration during mould micromilling
Along with the groove geometry, the density of the structures (i.e. how many grooves per millimetre) is the primary driving variables of interest [20]. For these reasons, high production accuracy is mandatory for reaching the required diffraction properties and therefore, reliable microproduction methodologies must be adopted. The selected structure in fact not only has to fulfil the optical requirements but must be also fully machinable. The production process should be capable of generating minimal surface roughness as well as underformed discontinuous steps and transitions to achieve highly efficient diffractive structures [10].

\section{Process chain for diffraction polymer components}

In order to fabricate polymer components characterized by the presence of a diffraction grating, it is necessary to design and develop a dedicated process chain exploitable for mass production. Therefore, micromilling and injection moulding could represent suitable technologies thanks to their extensive use in industry. Obtaining microfeatures on traditional mould steel with high surface finish directly using the micromilling process still represents a challenge due to the difficult control of the cutting process, affected by tool deflection and tool wear, but also due to chip and burr formation issues.

In this work, a complete and innovative process chain was developed (Fig. 1) exploiting a combination of micromilling, nickel-phosphorous coating and microinjection moulding.

The process chain is based on coated mould micromilling. It starts from the selection of suitable mould steel that is therefore milled and NiP coated (Fig. 1a-b-c). The adoption and machining of the NiP coating relieves the moulding base steel (Fig. 1a) choice that becomes less crucial for the final mould shape and surface finish. This fact allows the selection of a more machinable steel. In fact, in the second step (Fig. 1b), the 
mould insert is milled in order to obtain the final shape of the surface, considering the thickness of the coating that is applied in the third step (Fig. 1c). In fact, an electroless nickelphosphorous coating with high phosphorous content (>10\%) is applied on the workpiece surface (hardness 50 HRC). This coating presents good machinability, allowing reaching high surface finishing, with acceptable tool wear and precise feature shape. The machining target is to use the tip angle of a square end mill tool to create the blaze-gratings as showed in Fig.1d. This method is basically the same method that Sawada et al. proposed in [21], where $\mathrm{V}$-shaped micro-grooving were obtained by milling. In the present method, however carbides micro end mills are used. In this way, it is possible to obtain different grating pitches and geometries by varying the workpiece/tool angle and the depth of cut. Finally, the diffraction structure is replicated on the polymer components by the injection moulding process (Fig. 1e and f).

\section{Materials and methods}

\subsection{Micromilling}

The milling operations were carried out in an ultra-accurate micromilling centre equipped with a $50 \mathrm{krpm}$ spindle (Kern Evo) (Fig. 2). To have the maximum accuracy, the machine was used in 3-axis configuration, while the 4th and 5th axes were not installed. The machine axis accuracy and repeatability supported the tight positioning tolerance required by the studied mould-making application. An optical presetter (Marposs VTS, Visual Tool Setter) was adopted for measuring the tools onboard. The machine thermal behaviour and stability, given by the synthetic concrete basement, were further enhanced by starting the cutting tests after having fully reached the thermal spindle stability after each change of cutting speed.

Uncoated solid carbide flat end mills (Zecha 481.030) were adopted (number of flutes: 2; cutting diameter: $0.3 \mathrm{~mm}$; maximum cutting length: $0.3 \mathrm{~mm}$ ). Three units were used, two for the preliminary experiments and one for the final mould that was used for injecting the parts. Flying run-out of all the adopted tools, measured with warm spindle at the rotational cutting speed with the Marposs VTS, was under $1 \mu \mathrm{m}$. At the visual inspection at the scanning electron microscopy, the different tool units adopted in this study showed to be entirely similar, indicating good tool repeatability. The cutting edge radius of the tools was small. It was quantified in the range of $1.5-2.5 \mu \mathrm{m}$ as average values for all the different tool units tested at different axial positions by using a 3D microscope (Alicona Infinite Focus G4). At the same time, corner radii were quantified on the new tool units to be around $3.5 \mu \mathrm{m}$ (Fig. 2).

\subsection{Micromilling of the NiP coating}

Process setup In this study, one NiP mould insert (steel substrate AISI H13, 46-48HRC - coating Nickel Phosphorous, $50 \mathrm{HRC}$ ) was adopted to focus the feasibility analysis on the diffraction gratings. The machining of the gratings was obtained by exploiting the inclined peripheral milling with a flatend milling tool (Fig. 3) as depicted in the following picture:

The basic equations governing the cutting kinematic are as follows.

The radial depth of cut is determined by the input grating parameters (Eq. 1):

ae $=Z$ step $\cdot \cot \varphi$

The axial depth of cut varies due to the inclined planes (Eqs. 2-3):

$$
\begin{aligned}
\operatorname{ap}_{\max }= & Z \text { fix }+\frac{D}{2} \cdot \operatorname{tg} \varphi=Z \text { fix }+\frac{D}{2} \frac{Z \text { step }}{\mathrm{ae}} \\
\mathrm{ap}_{\min }= & Z \text { fix }+\left(\frac{D}{2}-\mathrm{ae}\right) \cdot \operatorname{tg} \varphi=Z \text { fix }+\left(\frac{D}{2}-Z \text { step } \cdot \cot \varphi\right) \cdot \operatorname{tg} \varphi=Z \text { fix } \\
+\left(\frac{D}{2} \cdot \operatorname{tg} \varphi-Z \text { step }\right) & =Z \text { fix }+\left(Z \operatorname{step}\left(\frac{D}{2 \mathrm{ae}}-1\right)\right)
\end{aligned}
$$

\begin{tabular}{|c|c|c|c|c|c|c|c|c|c|}
\hline Zone & & $\begin{array}{l}\text { Angle } \varphi \\
\left.{ }^{\circ}\right]\end{array}$ & $\begin{array}{l}Z- \\
\text { step } \\
{[\mu \mathrm{m}]}\end{array}$ & $\begin{array}{l}H \\
{[\mu \mathrm{m}]}\end{array}$ & $\begin{array}{l}P \\
{[\mu \mathrm{m}]}\end{array}$ & & $\begin{array}{l}f_{\mathrm{z}} \\
{[\mu \mathrm{m}]}\end{array}$ & $\begin{array}{l}\mathrm{Vc} \\
{[\mathrm{m} / \mathrm{min}]}\end{array}$ & $\begin{array}{l}D \\
{[\mu \mathrm{m}]}\end{array}$ \\
\hline$\# 1$ & \multirow[t]{6}{*}{ Grating geometry } & 7 & 3 & 2.97 & 24.6 & Milling & 1 & 21 & 300 \\
\hline$\# 2$ & & & & & & & 1.5 & & \\
\hline$\# 3$ & & & & & & & 2 & & \\
\hline$\# 4$ & & 12 & & 2.93 & 14.4 & & 1 & & \\
\hline$\# 5$ & & & & & & & 1.5 & & \\
\hline \#6 & & & & & & & 2 & & \\
\hline
\end{tabular}

Table 1 Micromilling experiments table 

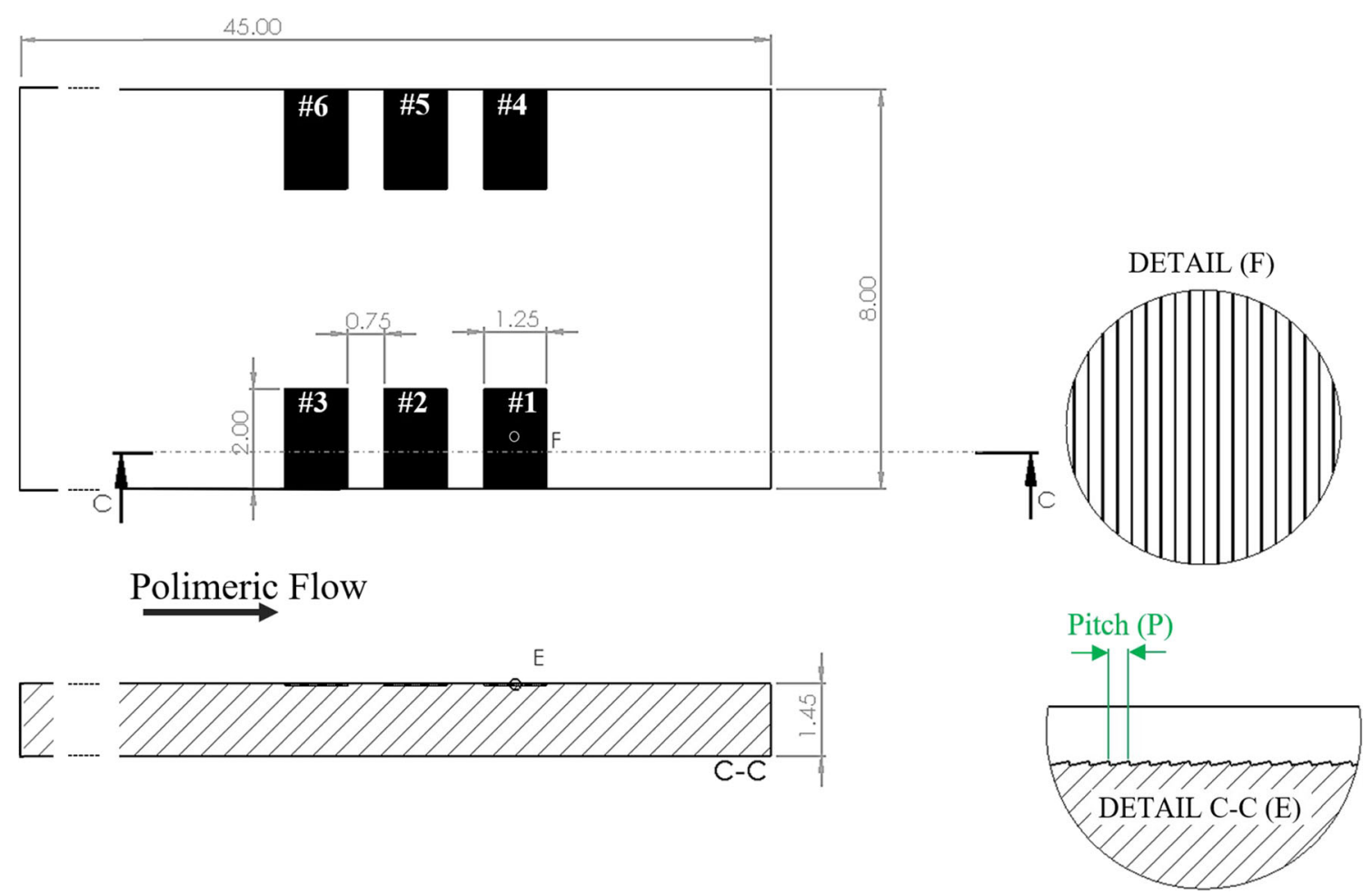

Fig. 4 Tested specimen geometry with the six zones machined

The grating Pitch and the Height are (Eqs. 4-5):

$P=\frac{\text { ae }}{\cos \varphi}=Z$ step $\cdot \cot \varphi \frac{1}{\cos \varphi}=\frac{Z \text { step }}{\sin \varphi}$

$H=Z$ step $\cdot \cos \varphi$

Cutting procedure The micromilling procedure applied to the tested NiP-coated mould consisted of the following steps:

i. Selection of the inclination angle $\varphi$ and grating Pitch $P$

ii. Mould fixturing with the given inclination angle $\varphi$

iii. Setting part zero position at the centre of each milling zone (touch probe cycle)

iv. Setting of the Zfix value (the static tool engagement) as the axial negative offset of the tool centre during the cutting operations with respect to the touch probe position

v. Zones milling from 1 to 3

Table 2 Microinjection moulding parameters

\begin{tabular}{llll}
\hline Material & $T_{\text {melt }}\left[{ }^{\circ} \mathrm{C}\right]$ & $T_{\text {mould }}\left[{ }^{\circ} \mathrm{C}\right]$ & $P_{\text {holding }}[$ bar $]$ \\
\hline ABS & 240 & 80 & 420 \\
PMMA & 260 & 100 & 450 \\
PC & 320 & 120 & 550 \\
\hline
\end{tabular}

- Milling of the (first) milling slot

- $Z$ disengagement

- Tool repositioning with incremental coordinates $X=$ $X+$ ae; $Z=Z+Z$ step

(repeat 50 times)

End

vi. Repositioning of the insert on the vise $180^{\circ}$ around $Z$ axis (and repositioning of the $X$ axis and $Z$ axis to obtain alignment between zones $4-6$ with the zones $1-3$ )

vii. Repeating steps from $\mathrm{i}$ to $\mathrm{v}$ to mill the zones from 4 to 6

The input parameters are the inclination angle and the Zstep, which define the diffractive surface characteristics (Table 1). Based on that, the radial tool engagement is defined (Eq. 1). The tool axial engagement is not constant along the cutting edge trajectory and is determined by the adopted tool diameter (Eqs. 2-3). This fact generates potentially different surface responses due to different forces along the cutting edge path. Height and Pitch of the diffractive texture are a direct consequence of the tool engagement conditions (Eqs. 4-5).

By adopting an uphill strategy (the tool goes up when passing from one step to next one), the burr generation on the final grating is limited since tool re-machines the generated topburr as confirmed by the preliminary cutting experiments.

Other than the definition of the tool engagement parameters, the micromilling process also requires a set of suitable 


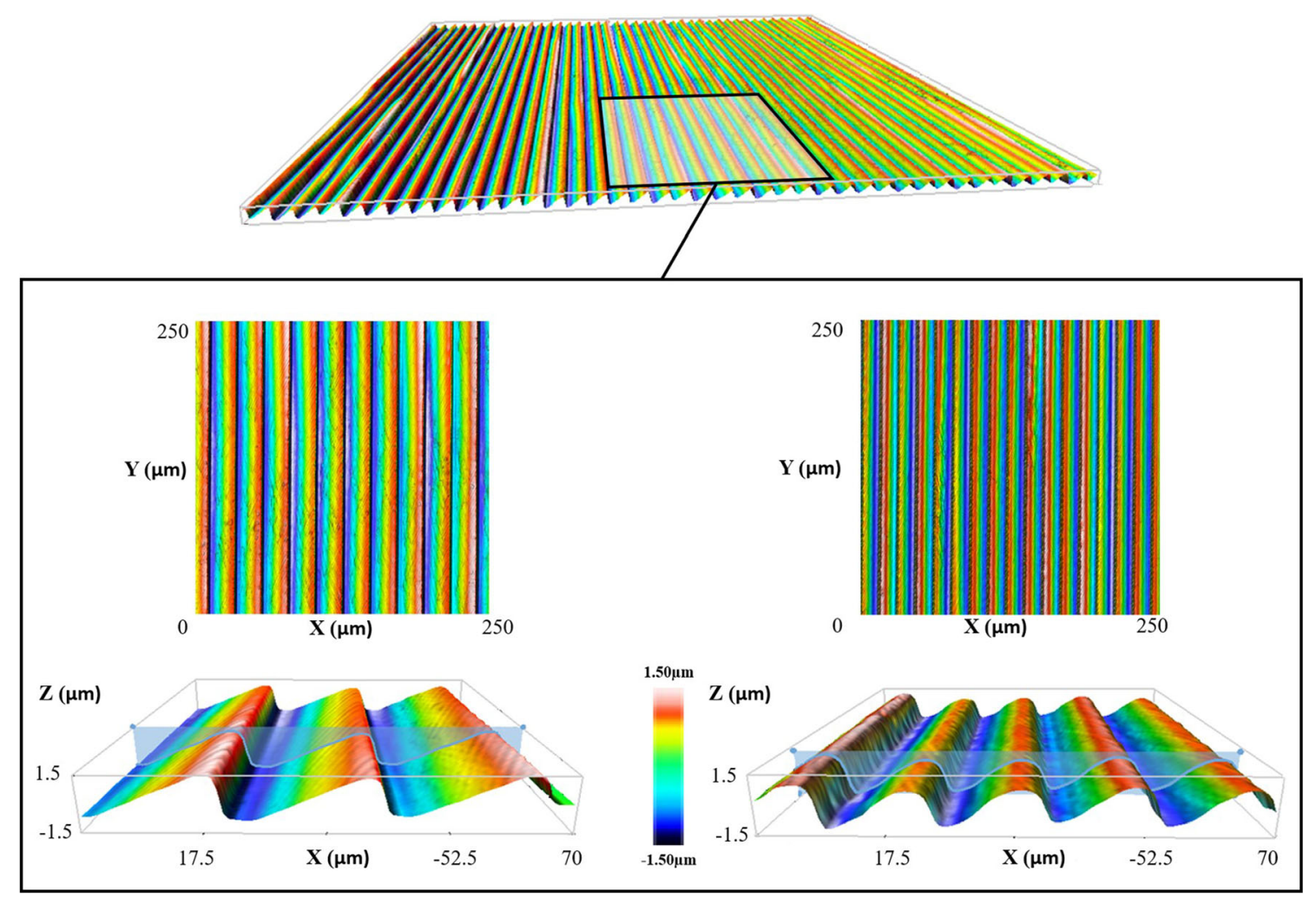

Fig. 5 3D topography extrapolated in the zone 1 (left) and in the zone 4 (right) on the mould

process parameters such as feed and cutting velocity that affect the cutting forces and therefore the cutting response.

Six different zones were therefore machined on the final mould for microinjection. Each of these zones was composed of 50 parallel slots. Each zone was machined with a different feed per tooth and surface inclination angle, according to Table 1 and Fig. 4. In this way, the effects of different machined roughness can be pointed out. The process parameters and the cutting strategy were based on preliminary tests performed on the same coating material (whose results are not presented in this manuscript).

a. Microinjection moulding

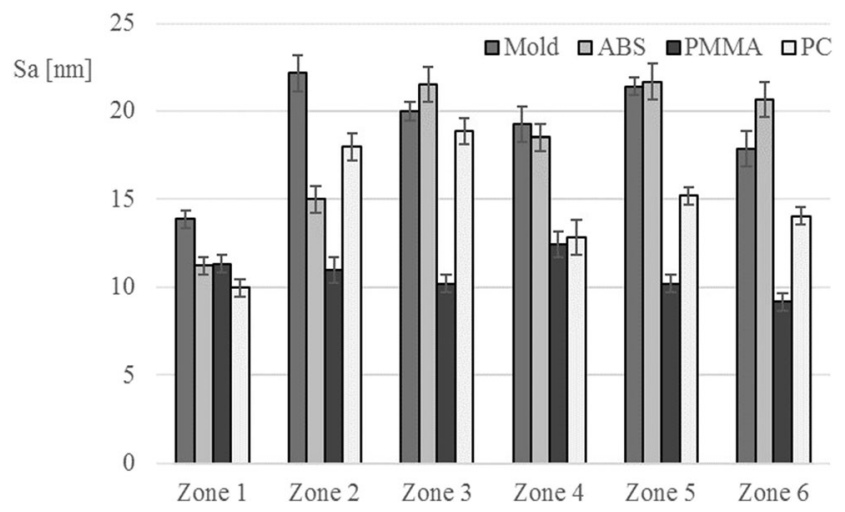

Fig. 13 Average surface Heights Sa obtained on mould and injected components
An injection moulding experimental campaign was carried out on a microinjection moulding machine (WittmannBattenfeld. Micropower 15) by replicating the diffractive gratings on three different polymers. A large batch of components was produced for each material and three components for each material were randomly selected for the accurate surface gratings analysis. The adopted setup is suitable for mass production of polymer precision components due to the independence of the plasticizing system and the injection system, allowing the fast and accurate filling of the mould cavity. Specifically, a polycarbonate (PC), a polymethyl methacrylate (PMMA) and an acrylonitrile butadiene styrene (ABS) were chosen because of their wide applicability in the optical field. Both the injection moulding parameters mould and melt temperature were set in the high range values of the material supplier datasheet to maximize the replication of the diffractive microfeatures. The significant injection process parameters are reported in Table 2. The movable mould part was designed to allow hosting an exchangeable insert, giving a final thickness of $1.45 \mathrm{~mm}$ to the components.

b. Surface characterization

The microstructured mould surface was firstly detected using a high-resolution scanning electron microscope (SEM, QUANTA FEI 400). Moreover, a 3D confocal microscope (Sensofar, PLU Neox) with $\mathrm{a} \times 20$ and $\mathrm{a} \times 100$ objective, operating in confocal mode, was exploited to characterize 
a)
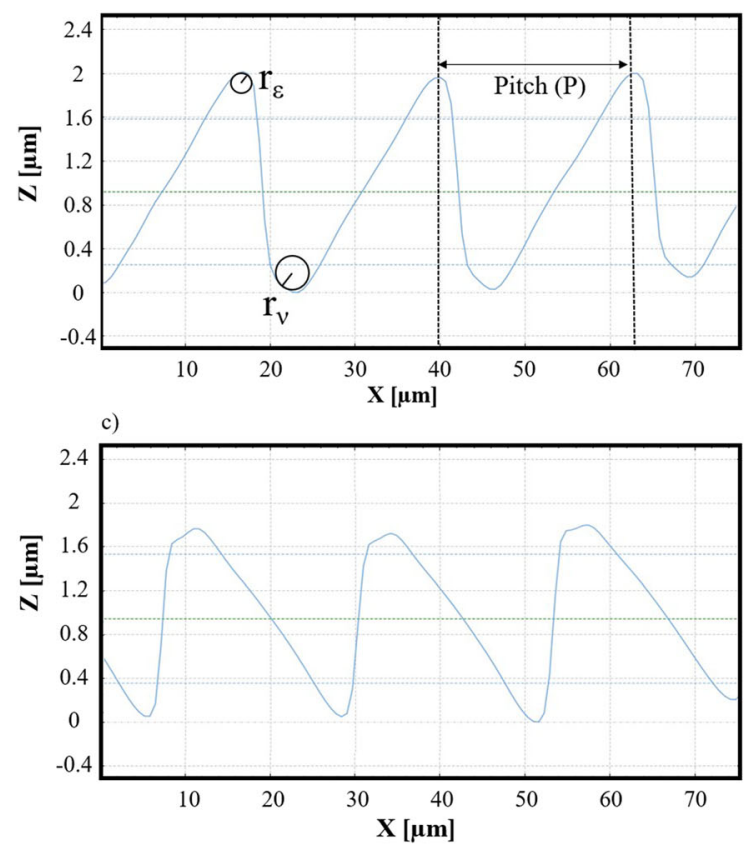

b)
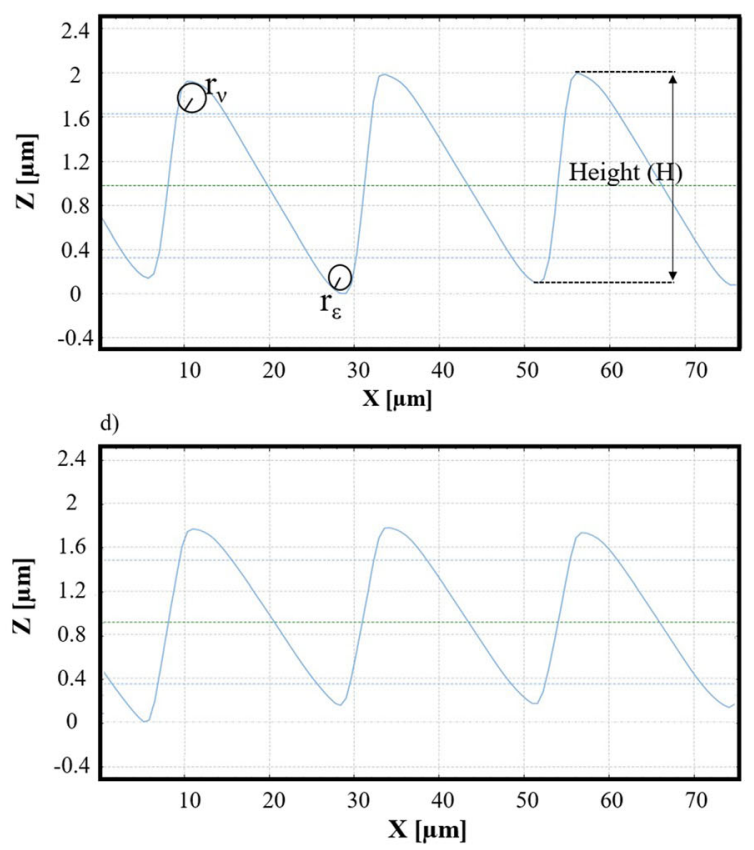

Fig. 8 2D profiles obtained on mould and polymer components (zone 1): (a) mould, (b) ABS, (c) PMMA, (d) PC

both the milled and the moulded diffractive gratings. A large effort was put in this analysis since in total 1296 measures were extracted and analyzed. In particular, for each of the six zones (Table 1), two different acquisitions were carried out. The first one is a stitched area of $900 \times 1200 \mu \mathrm{m}$, acquired to characterize the profile of the grating, a sort of "macroroughness" of the textured surface. The second one is a stitched area of $10 \times 200 \mu \mathrm{m}$, acquired along a single grating direction, to evaluate the "microroughness" of each feature. The macroroughness was characterized acquiring three areas for each zone (taken randomly and partially overlapped), while for the microroughness, multiple acquisitions were performed by sampling 15 areas per zone (taken randomly, but not overlapped, on the slots). At first, the mould topographies were aligned with the polymer ones using the software Cloud Compare and its built-in functions. Subsequently, for each

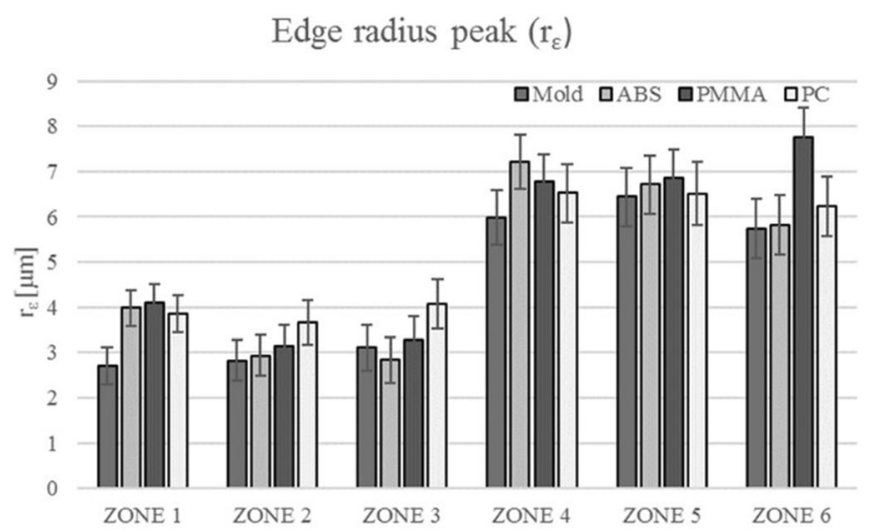

acquisition, the roughness parameters were evaluated according to ISO 25178 and ISO 4288 standards. The height of the profiles was calculated acquiring six measuring profiles, containing ten grating slots, and for each profile, three peak-valley distances were measured after removing the shape with the most proper geometrical filters.

\section{Results and discussion}

\subsection{Surface grating characterization}

\subsubsection{Micromilled mould}

Micromilling operations on the mould were run consistently. Micromilled surface generation did benefit from the NiP

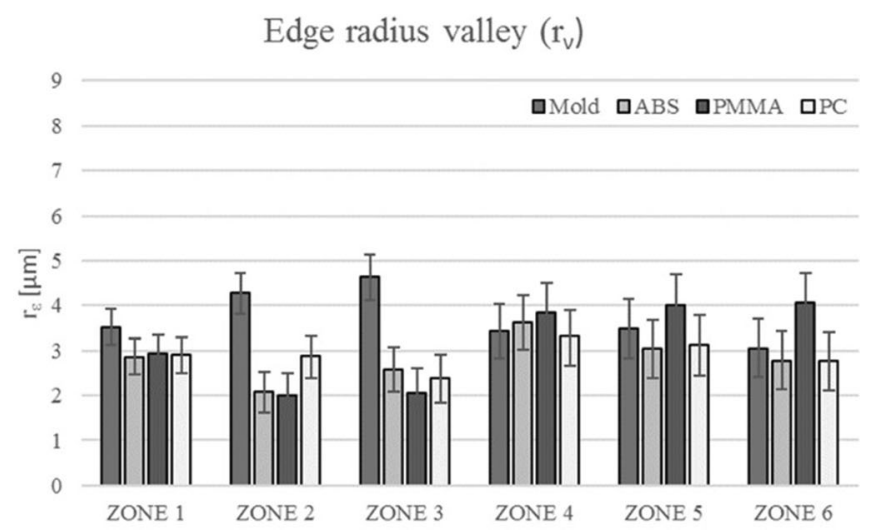

Fig. 9 Edge radii on mould and injected parts. Error bars are the standard deviation $\delta$ 
Table 3 Measured Height $(H)$ : Average and standard deviation (brackets) of 15 wavelengths in the gratings. \% represents the deviation percentage with respect to the mould Height

\begin{tabular}{lllllll}
\hline & Zone \#1 & & Zone \#2 & & Zone \#3 & \\
& Height $[\mu \mathrm{m}]$ & $\%$ & Height $[\mu \mathrm{m}]$ & $\%$ & Height $[\mu \mathrm{m}]$ & $\%$ \\
Mould & $1.98(0.10)$ & 100 & $1.97(0.06)$ & 100 & $1.99(0.07)$ & 100 \\
ABS & $1.87(0.09)$ & 94 & $1.84(0.06)$ & 93 & $1.85(0.07)$ & 93 \\
PMMA & $1.84(0.05)$ & 93 & $1.68(0.06)$ & 85 & $1.72(0.09)$ & 87 \\
PC & $1.84(0.07)$ & 93 & $1.83(0.10)$ & 93 & $1.81(0.06)$ & 91 \\
& Zone \#4 & & Zone \#5 & & Zone \#6 & \\
& Height $[\mu \mathrm{m}]$ & $\%$ & Height $[\mu \mathrm{m}]$ & $\%$ & Height $[\mu \mathrm{m}]$ & $\%$ \\
Mould & $1.91(0.13)$ & 100 & $1.86(0.13)$ & 100 & $1.82(0.12)$ & 100 \\
ABS & $1.75(0.14)$ & 92 & $1.62(0.12)$ & 87 & $1.59(0.13)$ & 87 \\
PMMA & $1.60(0.13)$ & 84 & $1.28(0.11)$ & 69 & $1.18(0.09)$ & 65 \\
PC & $1.68(0.11)$ & 88 & $1.62(0.12)$ & 87 & $1.51(0.11)$ & 83 \\
\hline
\end{tabular}

coating material, which gave an excellent finish response without inducing evident tool wear nor irregular cutting conditions. This fact confirms the past machining experiences that the authors had with this material [17]. The obtained grating surfaces showed a high level of reproducibility and homogeneity. All the six zones, machined with different parameters, resulted clean from process debris, burr-free, and with excellent surface finish that reached the best value of $\mathrm{Sa}=14 \mathrm{~nm}$ (Fig. 5 and Fig. 13). There was not any relevant difference in terms of surface homogeneity among the six different zones. These two inclination angles led to two different grating geometries, the first with an average Pitch of $23 \mu \mathrm{m}$ and an average Height of $1.98 \mu \mathrm{m}$, and the second one with an average Pitch of $15 \mu \mathrm{m}$ and an average Height of $1.86 \mu \mathrm{m}$, that generated different diffractive responses. All the slots showed a constant profile generation along the longitudinal direction, meaning that the machine accuracy was sufficient for the

Table 4 Measured Pitch $(P)$ : Average and standard deviation (in bracket) of 15 wavelengths in the gratings. \% represents the deviation percentage with respect to the mould Pitch

\begin{tabular}{lllllll}
\hline & Zone \#1 & & Zone \#2 & & Zone \#3 & \\
& Pitch $[\mu \mathrm{m}]$ & $\%$ & Pitch $[\mu \mathrm{m}]$ & $\%$ & Pitch $[\mu \mathrm{m}]$ & $\%$ \\
Mould & $22.9(0.2)$ & 100 & $22.9(0.2)$ & 100 & $23.0(0.2)$ & 100 \\
ABS & $22.7(0.2)$ & 99.1 & $22.7(0.2)$ & 99.1 & $22.8(0.2)$ & 99.1 \\
PMMA & $22.8(0.2)$ & 99.6 & $22.8(0.2)$ & 99.6 & $22.8(0.2)$ & 99.1 \\
PC & $22.7(0.2)$ & 99.1 & $22.8(0.2)$ & 99.6 & $22.8(0.2)$ & 99.1 \\
& Zone \#4 & & Zone \#5 & & Zone \#6 & \\
& Pitch $[\mu \mathrm{m}]$ & $\%$ & Pitch $[\mu \mathrm{m}]$ & $\%$ & Pitch $[\mu \mathbf{m}]$ & $\%$ \\
Mould & $15.1(0.1)$ & 100 & $15.2(0.1)$ & 100 & $15.2(0.1)$ & 100 \\
ABS & $15.0(0.1)$ & 99.3 & $15.1(0.2)$ & 99.3 & $15.1(0.2)$ & 99.3 \\
PMMA & $15.1(0.1)$ & 100 & $15.1(0.1)$ & 99.3 & $15.1(0.1)$ & 99.3 \\
PC & $15.1(0.2)$ & 100 & $15.0(0.1)$ & 99 & $15.1(0.2)$ & 99.3 \\
\hline
\end{tabular}

scope. Also, machine and spindle thermal effects were not seen on the mould surfaces, confirming that the process heat generation was not an issue for the cutting operation. However, the geometry of the gratings (i.e. the $2 \mathrm{D}$ profile that can be obtained by sectioning them) showed some deviations with respect to the nominal grating profiles. In particular, the obtained blaze-gratings look rounded (with rounded upper and bottom edges) (Figs. 8a and 9). The bottom edge roundness was mainly introduced by the tool shape and its corner radius. In fact, by observing Fig. 5 and the edge data analysis of Fig. 9, it is possible to note that the zones 1-2-3 and the zones 4-5-6 present different rounding values. On one side, zones 1-2-3 present a roundness value that is compatible with the nominal corner radius of the tools while the other zones present increasing rounding values, that almost doubled. Not only the nominal tool geometry is expected to have played a role in the rounding definition but also cutting issues like tool deflections induced by cutting forces and elastic recovery of the material (the two sets of zones present different tool engagements and therefore generate different cutting force values).

Another profile deviation characterizing the manufactured mould gratings was observed in terms of Height and Pitch that resulted smaller than the nominal ones of about 1-2 $\mu \mathrm{m}$ (compare Table 1 and Tables 3 and 4). Similarly to what happened for the profile rounding, these deviations could have been determined by the tool corner radius, the elastic response of the material and the tool radial deflections caused by cutting forces. It must be noted that a possible effect on this deviation could have been introduced by the intrinsic machine errors producing not-perfectly-aligned peaks and valleys (Fig. 6). These errors are quantified in the range of $0.5-1 \mu \mathrm{m}$ and partially contribute to the overall profile geometry error.

Another interesting phenomenon that was observed, though very limited, was a tendency of the tool to generate cutting passes with diminished surface quality (Fig. 7). These slots showed inferior surface quality due to the significant presence of ploughing marks that can be attributed to chip re-machining issues. This fact is confirmed by SEM scanning of tools after cutting (Fig. 7) that appears full of chips and debris, although the slots were typically clean.

The limited presence of these low-quality slots was not expected to play a role in the optical response, but further investigations are needed to deepen this issue in the future.

All these deviations from the nominal geometry can induce variation on the diffraction properties. In particular, the transition regions - i.e. where the rounding effect produced by the tool is present - generate a direct effect on light diffraction as discussed in [22]. The rounding edges, inevitable at micro/ nanoscale, tend to act as scatterer themselves thus introducing a potential limitation to the diffraction properties. This effect is presumably proportional to the ratio between the surface area of the rounding and the overall surface area. Of course, the 

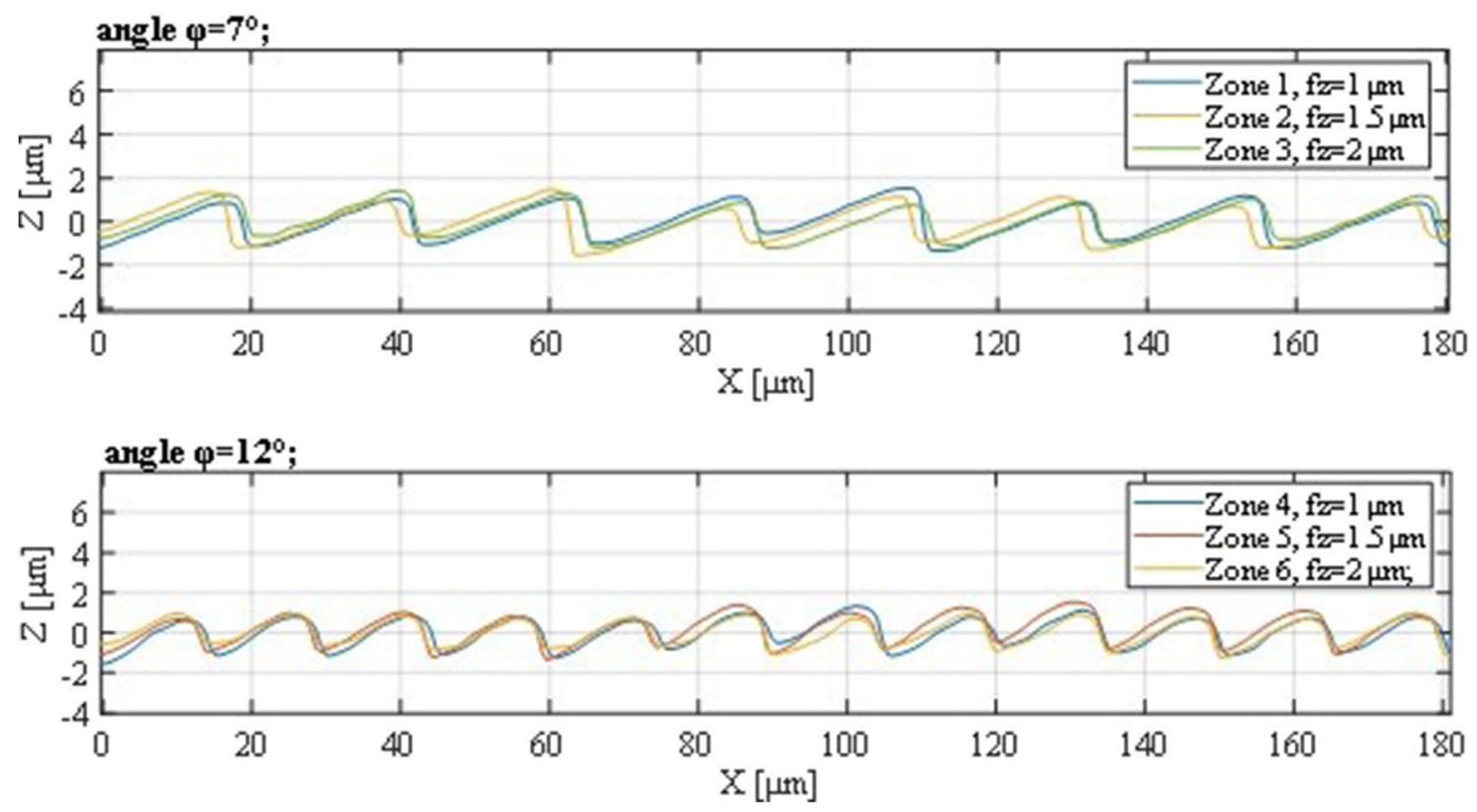

Fig. 6 Grating profiles obtained on the mould

more transition regions there are, the more scatter there will be from them. For these reasons, regularity of the rounding is another important driving factor for the diffraction performance.

\subsubsection{Micro moulded parts}

Macroroughness: profile shape The injected diffraction gratings were characterized using an optical profilometer operating in confocal mode. In order to better investigate qualitatively the feature replication, the peak edge radius $r_{\varepsilon}$ and the valley edge radius $r_{v}$, defined as showed in Fig. 8, were measured. It was found that the mould $r_{\varepsilon}$ was well replicated by the whole polymers (Fig. 9). In particular, the $r_{\varepsilon}$ of the injected components is larger than the mould ones, due to the natural shrinkage occurred during the cooling phase that rounds the corners. Conversely, the polymer $r_{v}$ for the whole zones is quite constant for the zones 1-2-3 (range 2-3 $\mu \mathrm{m}$ ) and zones 4-5-6 (range 3-4 $\mu \mathrm{m}$ ). In particular, the PMMA $r_{v}$ values are larger than the ABS and the PC ones for the zones 4-5-6 in which it presents the worse filling rate, according to the Height and Pitch reduction show in Tables 3 and 4. Therefore, it can be said qualitatively that the different feature shapes and the different polymers led to different replications, influencing the final radius of the replicated grating.

The feature Height results show that all the polymers replicated the grating profiles in all the six zones (Table 3 and Fig. 12). In particular, ABS was able to achieve the best surface replication, about $94 \%$ for the zones 1-2-3, while the parts made of PMMA presented the worse geometric trueness, with the worst result equal to $65 \%$. In general, the gratings of the zones 1-2-3 were better replicated by the whole polymers, due to the larger pitch of microfeatures.

Furthermore, the zone 1 and the zone 4, that are farther from the gate, are characterized by the best replication. This agrees to Xu et al. [23] that reported about the influence of the position of the microfeatures on their replication. In fact, the polymer undergoes a shorter cooling time in these zones with respect to the other four zones. In this way, the polymer is affected by the increase of the cavity pressure with a consequent improvement of the replication.

The Pitch variations, due to the polymer shrinkage and warpage, were measured for 15 gratings in a row, finding a deviation of about $1 \%$ that can be considered negligible for
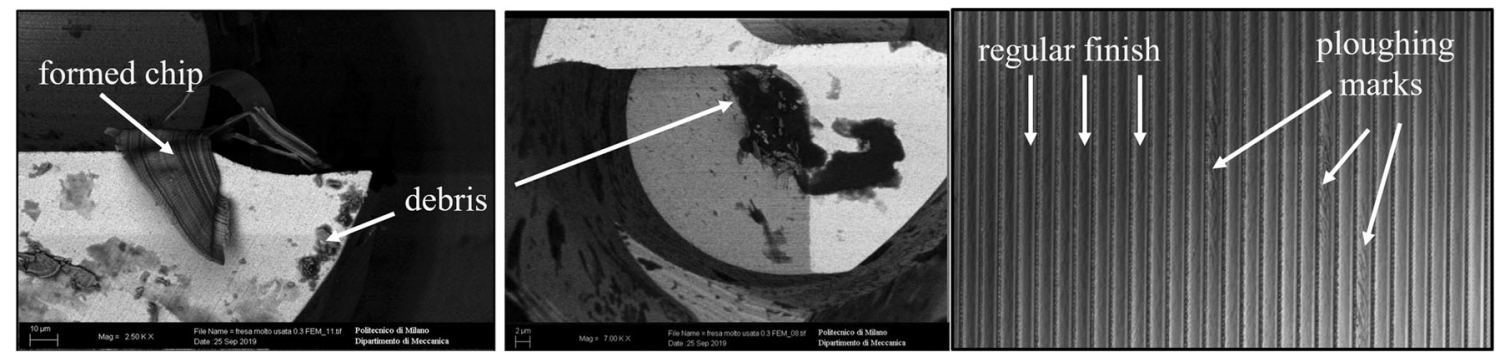

Fig. 7 Replicated gratings on the mould (zone 1, central part) 


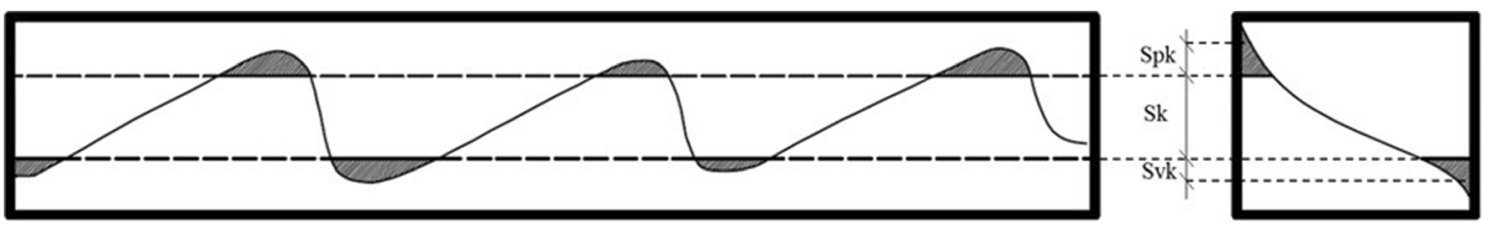

Fig. 10 Scheme of the used areal parameters on the grating profile

aesthetic applications in which the detector is represented by the human eye (Table 4). Otherwise, for security and sensing application, a nanometric range repeatability is required [2].

Common roughness parameters, such as $\mathrm{Sa}$ or $\mathrm{Sq}$, are not suitable to characterize the form and the replication of microgratings due to their intrinsic characteristics that based on a sort of symmetry of the roughness profile [24]. Recent studies [25-27] showed how the material ratio curve could give information about the surface topography. In fact, the Abbott-Firestone curve is representative of the material distribution along the height of a roughness profile [25] and the comparison of the curves could be used to predict the smoothing effects due to tribological wear [26] or to evaluate the oil lubricating capability exploiting the sum of the parameters Svk, Spk ad Sk [27].

In this work, in order to evaluate the mould/polymer shape trueness and find a correlation between the roughness parameters and the replication of the grating geometry, the parameters Svk, Spk and Sk were considered with the idea that their sum could be representative of the $2 \mathrm{D}$ grating profile as shown in Fig. 10. The sum of the parameters Svk, Spk and Sk has no physical significance, but compared to the mould one, for a repeated and regular profile (therefore macroroughness), gives an indication of "shape trueness" of the valleys, pulp and peaks. Certainly, this method is not rigorous for comparing random areal profiles or volumes because different profile shape could lead to equal sum. However, in this case, since the nominal shape is the same for both the mould and the moulded gratings, the same shape of the profile is implicitly already taken into account by the fact that the features of the gratings are regular and repeated. The indicator of trueness $\mathrm{Spk}+\mathrm{Svk}+\mathrm{Sk}$ can give an empirical estimate of global replication respect to the mould. Thus, a worse mould replication leads to a smaller sum. Each parameter was measured according to DIN 4776 (ISO 13565 Part 1). Furthermore, using an optical topography characterization setup, such as the profilometer, the measurement of Svk, Spk and Sk parameters is much faster and more immediate than the measurement of the grating's Heights.

The results reported in Fig. 11 show how the sum of Svk, Spk and Sk is linked to the replication of the grating geometry for all the six zones, with the ABS that best filled the mould. Therefore, their trend, expressed in percentage respect to the mould, is similar to the Height reduction, as shown in Fig. 12.

Microroughness: slot finishing The trend commented in the previous section is also confirmed for the microroughness, expressed in terms of Sa (Fig. 13), creating a parallelism
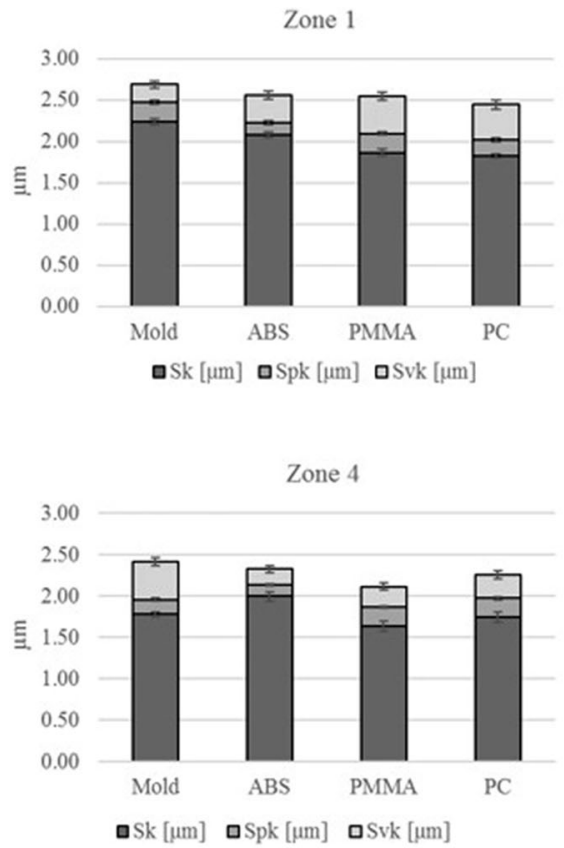
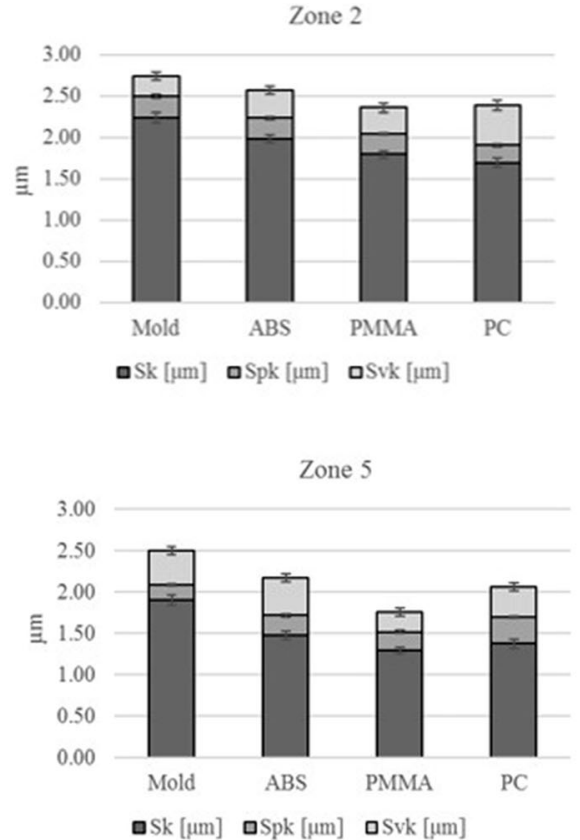
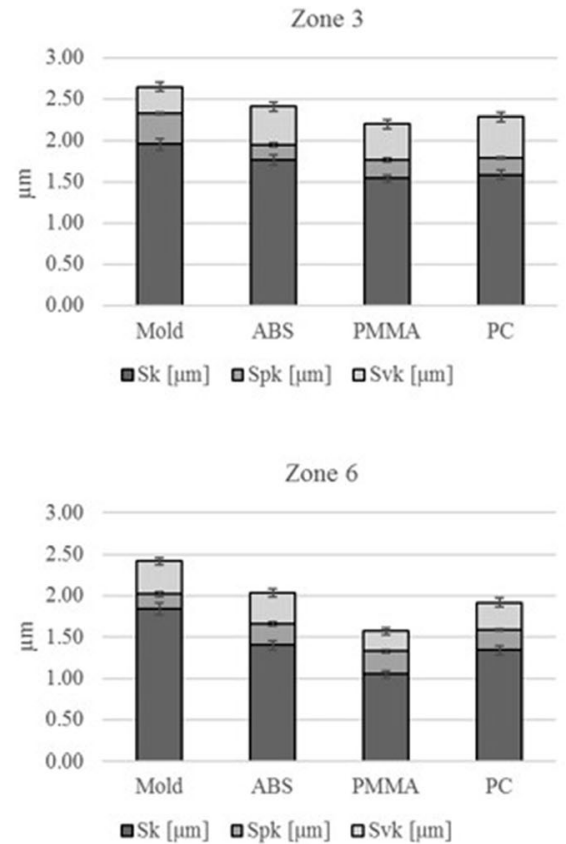

Fig. 11 Areal parameters obtained on mould and injected components 
Fig. 12 Percent reduction of Height and Svk, Spk and Sv sum for mould and moulded components for the six zones

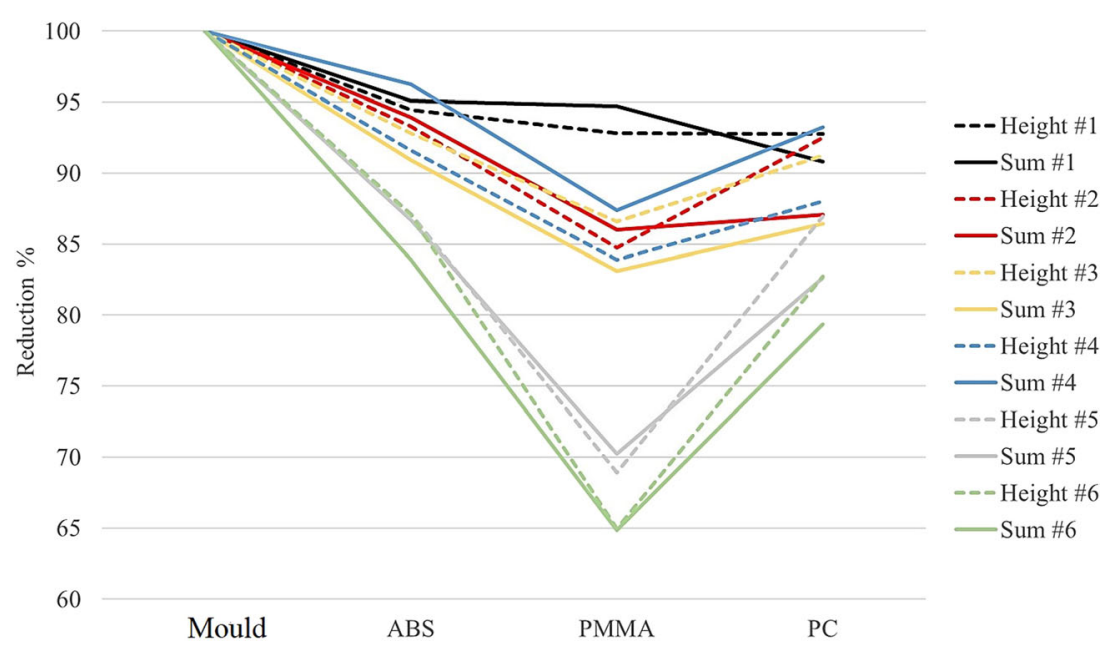

respect to the mould in terms of $\mathrm{Sa}$, with a better result of $9 \mathrm{~nm}$. This behaviour agrees with other literature results

[1]. between micro and macro surface profile replication. Thus, the PMMA lack of replication of micro valley/ peaks also leads to an improvement of the surface finish

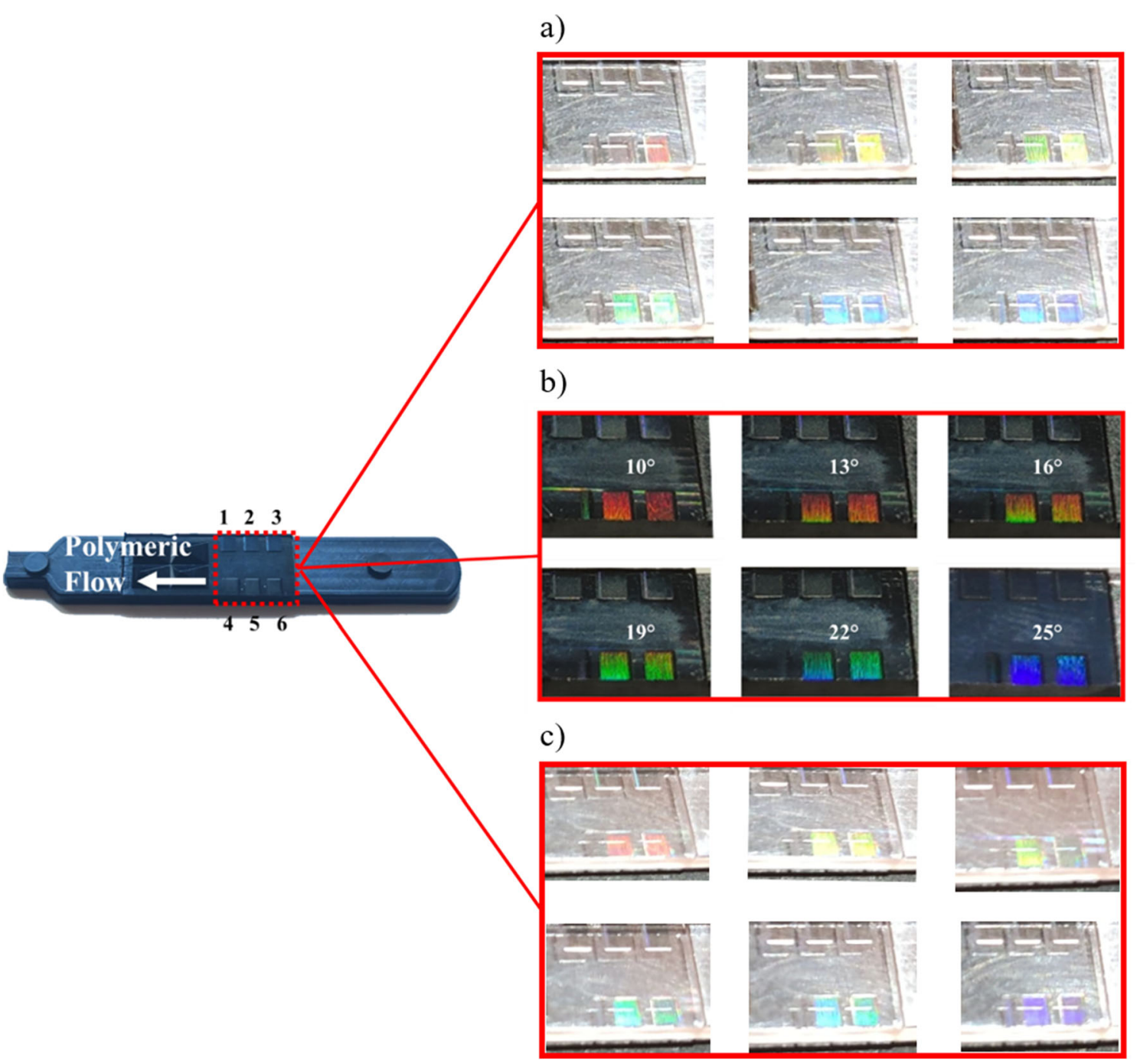

Fig. 14 Diffraction tests on the three injected materials: (a) PC, (b) ABS, (c) PMMA 
Preliminary optical response analysis A preliminary analysis was conducted on the printed specimens to confirm their diffraction properties. Figure 14 exhibits the diffraction of a $5000 \mathrm{~K}$ light source that illuminates the three material gratings at different incidence angles. Because of the chromatic dispersion, the hue perceived by the user changes by tilting the sample passing from red to blue, proving the diffraction effect along the visible light wavelength spectrum.

\section{Conclusions}

The main objective of the current study was to introduce and validate a completely new process chain for the fabrication of diffractive surfaces on injected polymeric components via textured NiP micromilled moulds.

There are two main scientific insights that are presented: (i) a new process chain is presented based on the implementation of an innovative cutting strategy of the mould coating able to achieve diffraction patterns on moulds with cheaper tools than diamond ones; (ii) the use of innovative NiP coating material for micromoulds applications. A blaze-diffraction grating was designed and micromilled on a NiP coating by means of a carbide $\varnothing 0.3 \mathrm{~mm}$ flat-end milling tool. Systematic deviations in terms Height and Pitch with respect to nominal blazegrating were obtained in the order of $1-2 \mu \mathrm{m}$ but repeatable profiles were obtained with different inclination angles $\left(7^{\circ}\right.$ and $12^{\circ}$ ) between the workpiece and the tool. The effect of the feed per tooth and other tool engaging parameters were proved to be not relatively significant on the overall surface roughness along with the grating slots (reaching a consistent extreme finish between $S a=14$ and $22 \mathrm{~nm}$ ). However, their effects on the grating profile were more relevant due to the impact of tool geometry, tool flexibility and process variability response. However, the high surface finishing, achieved for the whole feed per tooth and the tool/workpiece angle variations, proves the process robustness and the suitability of the NiP coating to manufacture microfeatures with negligible tool wear and no burr formation.

The diffraction gratings were replicated by ABS, PC and PMMA using the microinjection moulding process. ABS achieved the best results with an average replication of about $94 \%$ for the zones with inclination of $7^{\circ}$ and an average replication of about $89 \%$ for the zones with inclination of $12^{\circ}$. The latter are characterized by the smallest Pitch and Height. The sum of the roughness parameters Svk, Spk and Sk was used to characterize the replication of the diffraction gratings with the idea according to which it is representative of the polymer filling rate, finding parallelism with the structure's Height expressed as mould Height reduction.

Future studies will be devoted to investigating how the optical diffraction response varies with the topographic grating characteristics generated during the entire manufacturing process chain. Attention will be paid to the study of tool wear effects for what concerns micromilling and to the influence of injection moulding parameters on the grating replication and the consequent diffraction properties.

Acknowledgements The authors would like to thank Eng. Luca Simeon for his support in the execution of the milling experiments.

Author contribution All the authors conceived the experiments. NM and PP performed the experiments and data analysis (microinjection moulding and micromilling, respectively). NM and PP wrote the paper. MA, MS, GL revised the paper.

Funding Open Access funding provided by Politecnico di Milano.

Data availability The authors confirm that the data and material supporting the findings of this work are available within the article.

\section{Declarations}

Ethical approval Not applicable.

Consent to participate Not applicable.

Consent for publication Not applicable.

Conflict of interest The authors declare no conflicts of interest.

Open Access This article is licensed under a Creative Commons Attribution 4.0 International License, which permits use, sharing, adaptation, distribution and reproduction in any medium or format, as long as you give appropriate credit to the original author(s) and the source, provide a link to the Creative Commons licence, and indicate if changes were made. The images or other third party material in this article are included in the article's Creative Commons licence, unless indicated otherwise in a credit line to the material. If material is not included in the article's Creative Commons licence and your intended use is not permitted by statutory regulation or exceeds the permitted use, you will need to obtain permission directly from the copyright holder. To view a copy of this licence, visit http://creativecommons.org/licenses/by/4.0/.

\section{References}

1. Lu Y, Chen F, Wu X, Zhou C, Lou Y, Li L (2019) Fabrication of micro-structured polymer by micro injection molding based on precise micro-ground mold core. Micromachines 10:253. https://doi. org $/ 10.3390 / \mathrm{mi} 10040253$

2. Ruffato G, Pasqualotto E, Sonato A, Zacco G, Silvestri D, Morpurgo M (2013) Implementation and testing of a compact and high-resolution sensing device based on grating-coupled surface plasmon resonance with polarization modulation. Sensors Actuators B Chem 185:179-187. https://doi.org/10.1016/j.snb. 2013.04.113

3. Maystre D (2013) Comptes Rendus Physique; Diffraction gratings: An amazing phenomenon Réseaux de diffraction: Un curieux phénomène. C R Phys 14:381-392. https://doi.org/10.1016/j.crhy. 2013.02.003 
4. Luther-davies B, Freeman D, Madden S (2005) Fabrication of planar photonic crystals in a chalcogenide glass using a focused ion beam. 13:3079-3086. https://doi.org/10.1364/OPEX.13.003079

5. Romanato F, Kartasasmita H, Hong K, Ruffato G, Prasciolu M (2009) Interferential lithography of 1D thin metallic sinusoidal gratings: accurate control of the profile for azimuthal angular dependent plasmonic effects and applications. Microelectron Eng 86:573-576. https://doi.org/10.1016/j.mee.2009.01.080

6. Zeitner UD, Oliva M, Fuchs F, Michaelis D, Benkenstein T, Kley THE (2012) High performance diffraction gratings made by e-beam lithography:789-796. https://doi.org/10.1007/s00339-012-7346-z

7. Enqiang WMA, Ang LEW, Hang PEZ, Ei W, Hang Z, Ong BAS, Ai SHD (2019) Femtosecond laser direct writing of diffraction grating and its refractive index change in chalcogenide As 2 Se 3 film. Optics Express 27(21):30090-30101. https://doi.org/10.1364/ OE.27.030090

8. Kong H (2018) One-step generation of hybrid micro-optics with high-frequency diffractive structures on infrared materials by ultraprecision side milling. Optics Express 26(21):28161-28177. https://doi.org/10.1364/OE.26.028161

9. Davies MA, Dutterer BS, Suleski TJ, Silny JF, Kim ED (2012) Diamond machining of diffraction gratings for imaging spectrometers. Precis Eng 36:334-338. https://doi.org/10.1016/j. precisioneng.2011.09.006

10. Brinksmeier E, Gläbe R, Schönemann L (2012) Review on diamond-machining processes for the generation of functional surface structures. CIRP J Manuf Sci Technol 5(1):1-7, ISSN 17555817. https://doi.org/10.1016/j.cirpj.2011.10.003

11. Dornfeld D, Lee DE (2008) Precision manufacturing. SpringerVerlag US, p 775. https://doi.org/10.1007/978-0-387-68208-2

12. Brinksmeier E, Riemer O, Gläbe RM (2013) Fabrication of complex optical components -from mold design to product. SpringerVerlag, Berlin Heidelberg ISBN 9783642330001

13. Holthusen A, Riemer O, Schmütz J, Meier A (2017) Mold machining and injection molding of diffractive microstructures. J Manuf Process 26:290-294. https://doi.org/10.1016/j.jmapro.2017.02.014

14. Cheng K, Huo D (2013) Micro-Cutting: fundamentals and applications. John Wiley \& Sons, Chicheste, p 366 ISBN: 978047097287

15. Parenti P, Masato D, Sorgato M, Lucchetta G, Annoni M (2017) Surface footprint in molds micromilling and effect on part demoldability in micro injection molding. J Manuf Process 29. https://doi.org/10.1016/j.jmapro.2017.05.024

16. Masato D, Sorgato M, Parenti P, Annoni M, Lucchetta G (2017) Journal of Materials Processing Technology Impact of deep cores surface topography generated by micro milling on the demolding force in micro injection molding. J Mater Process Technol 246: 211-223. https://doi.org/10.1016/j.jmatprotec.2017.03.028
17. Milan N, Sorgato M, Parenti P, Annoni M, Lucchetta G (2020) Effects of micromilled NiP mold surface topography on the optical characteristics of injection molded prismatic retroreflectors. Precis Eng 61:126-135. https://doi.org/10.1016/j.precisioneng.2019.10. 006

18. Li D, Davoudinejad A, Zhang Y, Tosello G (2018) Evaluation of an improved micro milling strategy for the generation of tool steel micro features with optical functionality. In: Proceedings of WCMNM 2018 World Congress on Micro and Nano Manufacturing. https://doi.org/10.3850/978-981-11-2728-1_17

19. Kalima V, Pietarinen J, Siitonen S, Immonen J, Suvanto M (2007) Transparent thermoplastics: Replication of diffractive optical elements using micro-injection molding. 30:285-291. https://doi.org/ 10.1016/j.optmat.2006.11.046

20. Gerhard C (2018) Optics manufacturing - components and systems, 1st edn. CRC Press, Taylor \& Francis Group, Boca Raton, p 325. https://doi.org/10.1201/9781351228367

21. Sawada K, Kawai T, Takeuchi Y, Sata T (2000) Development of ultraprecision micro grooving (manufacture of V-shaped groove). JSME Int J Ser C Mech Syst Mach Elem Manuf 43(1):170-176

22. Schaub M, Schwiegerling J, Fest EC, Symmons A, Shepard RH (2011) Molded optics design and manufacture, series in optics and optoelectronics. CRC Press, Taylor \& Francis Group, Boca Raton, p 272. https://doi.org/10.1201/b10863

23. Xu G, Yu L, Lee LJ, Koelling KW (2005) Experimental and numerical studies of injection molding with microfeatures. Polym Eng Sci. https://doi.org/10.1002/pen.20341

24. Sorgato M, Masato D, Lucchetta G (2017) Effects of machined cavity texture on ejection force in micro injection molding. Precis Eng 50:440-448

25. Salcedo MC, Coral IB, Ochoa GV (2018) Characterization of surface topography with Abbot Firestone curve. Contemp Eng Sci 11: 3397-3407. https://doi.org/10.12988/ces.2018.87319

26. Pawlus P, Reizer R, Wieczorowky M, Krolczyk G (2020) Material ratio curve as information on the state of surface topography - a review. Precis Eng 65:240-258. https://doi.org/10.1016/j. precisioneng.2020.05.008

27. Georgescu C, Cristea GC, Dima C, Deleanu L (2017) Evaluating lubricating capacity of vegetal oils using Abbott-Firestone curve. Mater Sci Eng 174. https://doi.org/10.1088/1757-899X/174/1/ 012057

Publisher's note Springer Nature remains neutral with regard to jurisdictional claims in published maps and institutional affiliations. 